Document downloaded from:

http://hdl.handle.net/10251/80796

This paper must be cited as:

Pastor Soriano, JV.; García Oliver, JM.; López, JJ.; Vera-Tudela-Fajardo, WM. (2016). An experimental study of the effects of fuel properties on reactive spray evolution using Primary Reference Fuels. Fuel. 163:260-270. doi:10.1016/j.fuel.2015.09.064.

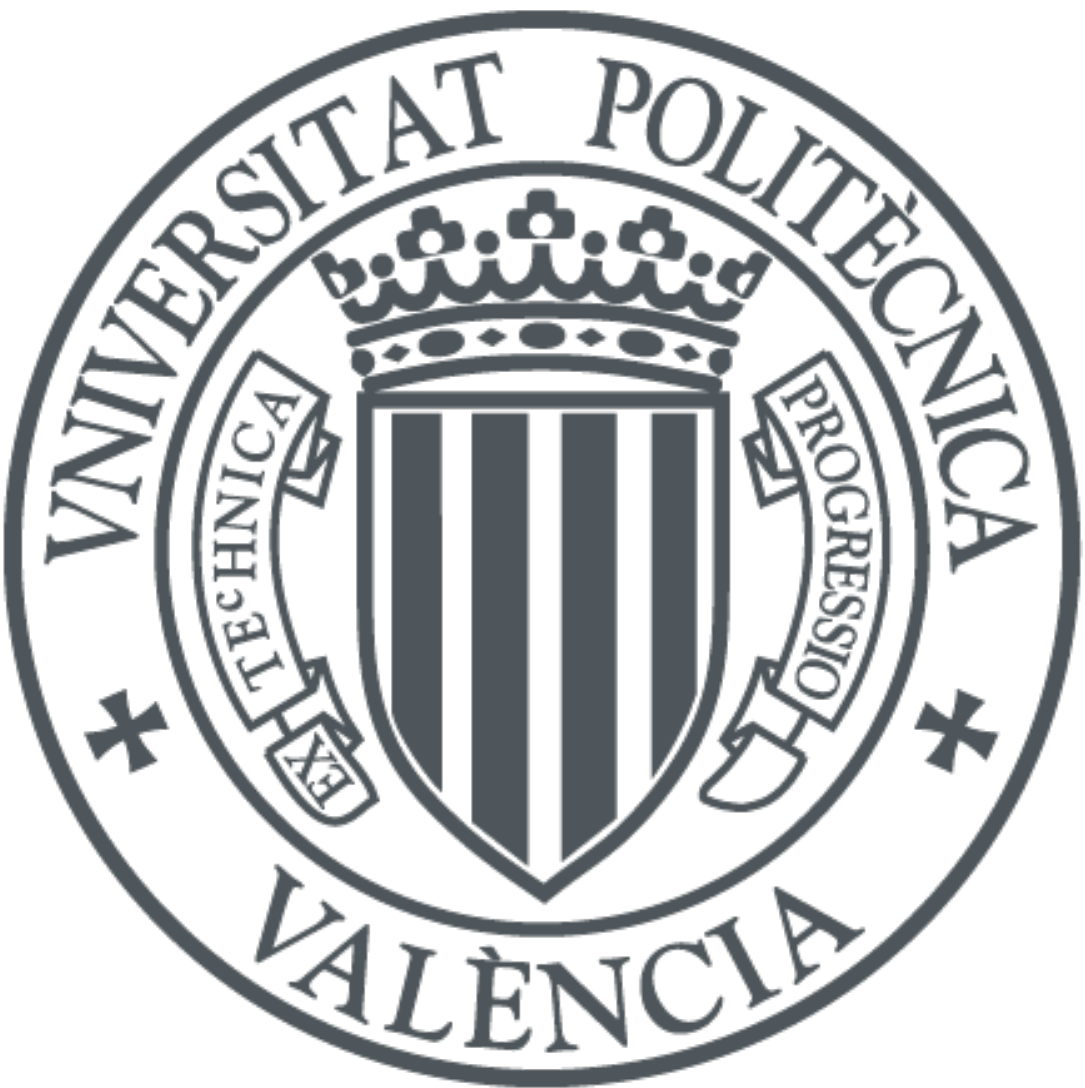

The final publication is available at

http://dx.doi.org/10.1016/j.fuel.2015.09.064

Copyright Elsevier

Additional Information 


\title{
An experimental study of the effects of fuel properties on reactive spray evolution using Primary Reference Fuels
}

\author{
J.V. Pastor, J.M. García-Oliver*, J.J. López, W. Vera-Tudela ${ }^{1}$ \\ CMT Motores Térmicos - Universitat Politècnica de València \\ Camino de Vera $s / n$ - 46022 Valencia, Spain
}

\section{Abstract}

An experimental study on the ignition and combustion of Diesel-type sprays using $n$-heptane, iso-octane and four intermediate blends is presented. The choice of components was done in order to represent the transition from conventional diesel fuel ( $n$-heptane) to a gasoline-like one (iso-octane) in terms of ignition behaviour. The experiments have been carried out in a high pressure high temperature vessel using specifications from the Engine Combustion Network (ECN). Parametric variations of oxygen concentration and air temperature have been performed for each fuel. In order to investigate the spray development, schlieren imaging for the quantification of spray penetration and ignition delay, $\mathrm{OH}^{*}$ chemiluminescence imaging for the lift-off length, and broadband radiation imaging for the soot intensity and flame length have been applied. The results show the large effect of mixture reactivity on the ignition times and lift-off length values. Regarding the effect

\footnotetext{
${ }^{*}$ Corresponding author Email address: jgarciao@mot.upv.es (J.M. García-Oliver)

${ }^{1}$ also from Pontificia Universidad Católica del Perú
} 
of the octane number of the blends on the ignition delay times, a linear effect has been found in the lower half of the blend range, while an exponential trend is evident in the top one. On the other hand, a scaling law for the stabilized flame length based upon momentum-controlled assumptions has shown that results are comparable to those obtained in the literature. Finally, the applicability of the results obtained on the performance and efficiency in real engines is discussed.

Keywords: Primary Reference Fuel, Diesel Spray, Ignition, Combustion, Lift-off Length

1. Introduction

The role of fuel properties on diesel engine performance and emission has 3 been an active field of research for a long time. In recent years, more detailed 4 studies in combustion vessels have helped understanding the fundamental 5 processes dealing with fuel effects on spray development and combustion. Different fuel types are within reseach focus, such as bio-diesel, synthetic 7 Fischer-Tropsch fuels, oxygenated fuels, diesel-gasoline blends and surrogate combustion strategies and fuel types to improve the engine efficiency and reduce the emission of pollutants. For example, a study with direct diesel injection and port gasoline injection showed that the higher amount of gasoline retarded the combustion phasing. This in turn lowered the heat transferred and allowed for the lowest fuel consumption, which also resulted in low $N O_{X}$ and $P M$ emissions [1]. Another study replaced entirely the diesel fuel with gasoline and also obtained less specific fuel consumption together with lower 
smoke levels [2]. Blends of gasoline and ethanol have also been used in diesel engines in order to study the effects on combustion and reduce the amount of diesel injected [3]. Results have shown reduction of soot levels, but at the cost of higher $N O_{X}$ and compromised combustion stability under some conditions. Furthermore, a similar study with blends and changes in the contour conditions also presented improvements in the combustion efficiency [4].

Among the most used fuels used for the evaluation of diesel-gasoline blends are those known as Primary Reference Fuels (PRFs), which represent both ends of the octane rating scale, namely $n$-heptane $(O N=0)$ and iso-octane $(O N=100)$. Such a difference in octane (and thus cetane) numbers makes them good representatives of diesel and gasoline, respectively, in terms of ignition and combustion. A very recent study [5] presents the ignition mechanism of $n$-heptane and iso-octane under various conditions, showing the expected increase of autoignition delay times when moving from $n$-heptane to iso-octane. Such results are also verified by experimental investigations [6], as the ignition delay of four different PRF blends was shown to increase as the composition of iso-octane augmented in the blends. Furthermore, engine tests also report an increase in the ignition delay times as the octane number of the fuel is larger [7, 8, 9]. Another work done with PRFs, diesel and gasoline, investigated the combustion recession after the end of injection [10]. The results showed that the fuels with highest cetane numbers presented the least lifted flames and the shortest combustion recession times. Analogously, the lift-off length and ignition delay time relationship was also studied under a wider range of conditions using conventional diesel and a PRF blend of similar properties [11. Although the trend was not very 
clear, there was a interaction implying that the condition with longest lift-off length also presented the longest ignition delay times.

The present work reports a fundamental investigation on the ignition and combustion behaviour of fuel sprays under Spray A conditions [12], with a detailed focus on fuel properties. For that purpose, binary blends of $n$ heptane and iso-octane, which are Primary Reference Fuels (PRFs), have been tested. In terms of ignition behaviour, such blends should be representative of a detailed transition from a conventional diesel fuel ( $n$-heptane) to a gasoline-like one (iso-octane). The main objective of this work is the experimental characterization of spray mixing, ignition and sooting processes. For each fuel blend, the test plan includes parametric variations of ambient temperature and oxygen concentration, which have the largest effect on spray ignition behaviour. Experiments have been conducted in a constant pressure vessel, where high ambient pressure and temperature conditions typical of Diesel engines can be reproduced. For each condition, high speed schlieren and broadband luminosity imaging have been used to compare ignition, combustion and sooting behaviour of all fuel blends; $\mathrm{OH}^{*}$ radical imaging has also been performed to measure lift-off length. The present contribution is structured as follows. After this introduction, both the experimental setup and the optical techniques employed will be presented. Test conditions will be summarized, and results of fuel effects will be analysed. Finally, the main conclusions from this study are drawn. 


\section{Experimental setup}

\subsection{High Temperature and High Pressure vessel}

Tests have been performed in a high temperature and high pressure test chamber where the thermodynamic conditions obtained in a Diesel engine at the time of injection can be obtained with a maximum ambient temperature of $1000 \mathrm{~K}$ and a maximum pressure of $15 \mathrm{MPa}$. Compared to similar facilities [13], it is possible to obtain nearly quiescent and steady thermodynamic conditions in the test chamber. More details can be found in [14].

\subsection{Optical setup}

Different optical techniques have been employed in these experiments. Schlieren imaging has been used to measure spray penetration and autoignition delay, broadband luminosity imaging has been used to assess sooting intensity, and $\mathrm{OH}^{*}$ chemiluminescence imaging has been used to measure flame lift-off length. Figure 1 presents a schematic of the optical arrangement.

\subsubsection{Schlieren imaging}

The spray evolution inside the combustion chamber has been recorded by schlieren imaging [15]. This technique is sensitive to the first spatial derivative of density within the combustion chamber, which makes it useful to detect spray boundaries and thus evaluate macroscopic spray scales, whether vaporizing or non-vaporizing, inert or reactive. This technique shows the boundary between vaporized liquid and background gas because of the refractive index differences that exist between them, additionally, density gradients are also created in the chamber as the vaporized liquid cools the 
ambient gas [16, 17]; such refractive index gradients are also present during combustion, as the high temperate creates low density regions. Therefore, this method is valid for inert and reactive conditions. For this technique, the spray has to be illuminated from one side by a collimated beam. The shadow produced by the spray is then gathered with a lens and at its focal length a diaphragm is positioned to produce the schlieren effect by eliminating the diverted light beams. The recorded image is then captured by a high speed camera in order to obtain a time resolved evolution of the spray.

An example of an schlieren image can be seen in Figure 2. The routine used for the processing was developed by Sandia National Laboratories as part of the ECN group and is available on-line [18]. The code is based on the successive calculation of two standard deviation images to remove the schlieren effect of the hot ambient gases and to detect the spray boundary. For every instant $\left(I_{t}\right)$, the processing routine subtracts the two preceding images $\left(I_{t-1} \& I_{t-2}\right)$, then a two-step derivative process highlights the zones where the pixels have changed due to either spray or background gas movement, then the image is segmented [19, 20, 21]. Once the boundaries have been defined, the spray penetration is calculated by the procedure shown in [17. Additionally, the ignition delay based upon schlieren images has also been calculated using the method described in [12, 16, 22], which relies on the change in refractive index of the mixture and the shortening of the penetration .

A schematic of the optical arrangement is shown in Figure 1. The spray has been illuminated from the left window and the light has been captured by a CMOS camera from the opposite side. The light from a Xenon lamp passed 
through a $1 \mathrm{~mm}$ diameter pinhole that simulates a single-point light source. The light was reflected on a $150 \mathrm{~mm}$ parabolic mirror to obtain collimated light. After passing through the spray, the light has been collected by a biconvex lens and at its focal point a $4 \mathrm{~mm}$ diaphragm has been positioned to produce the schlieren effect. A BG39 bandpass filter (360-580nm) was used to minimize soot radiation effects. A 10-bit Photron SA-5 CMOS high-speed camera equipped with a Nikon $50 \mathrm{~mm} \mathrm{f}=1: 8$ lens were used, image acquisition frequency was $42000 \mathrm{FPS}$ with exposure time of $4.18 \mu \mathrm{s}$ and a pixel $/ \mathrm{mm}$ ratio of 5.26 leading to a field of view of $97 \mathrm{~mm}$.

\subsubsection{Broadband radiation imaging}

The soot distribution and intensity inside the combustion chamber have been recorded by direct imaging. This technique records the flame broadband radiation, which corresponds to the soot thermal radiation during the diffusion combustion phase.

Figure 3 shows a sample image of broadband radiation. An average background image is calculated for each repetition and based on that image and a two constant thresholds, a mask is generated to define the region of interest. It is important to clarify that given the strong difference between the intensity levels in the soot onset area (in the vicinity of the lift-off) and further downstream, two threshold values (a lower one for the onset and a higher one for the tip) were selected in order to accurately detect the contour. Then, the area of the flame and cumulative digital intensity are computed, and based on those two values the specific intensity is obtained. Also, and in a similar way to the spray penetration, the soot onset length and soot penetration (or flame length) are obtained as the distance from the nozzle to the points 
closest and furthest away from the injector, respectively. After all cases have been processed, the normalized intensity and specific intensity are calculated taking into account the camera settings of exposure time and aperture. It is worth noting that the soot onset length is not a replacement of the lift-off length calculated by means of $\mathrm{OH}^{*}$ chemiluminescence, because significant amounts of soot do not form until downstream from the lift-off location [23].

A schematic of the optical arrangement is shown in Figure 1 as well. A $50 / 50$ beam splitter has been positioned in between the parabolic mirror and the left window with a $45^{\circ}$ angle so the camera axis could be parallel to the spray axis but the reflected image perpendicular to it. A 10-bit Phantom V12 CMOS high-speed camera equipped with a Zeiss $100 \mathrm{~mm} \mathrm{f}=2$ lens were used, image acquisition frequency was 42000FPS with exposure times ranging from 0.4 to $23.29 \mu \mathrm{s}$ and a pixel $/ \mathrm{mm}$ ratio of 7.23 leading ot a field of view of $105 \mathrm{~mm}$.

\subsection{3. $\mathrm{OH}^{*}$ Chemiluminescence imaging}

The lift-off length (LoL) was recorded by $\mathrm{OH}^{*}$ chemiluminescence imaging. This technique records radiation at $310 \mathrm{~nm}$, which is controlled by the $\mathrm{OH}^{*}$ radical, and thus of the lift-off length for diesel sprays [23]. The $\mathrm{OH}^{*}$ radical is a marker of the high temperature combustion [24], for example the one occurring at the lift-off length. Additionally, the band at $310 \mathrm{~nm}$ is the strongest one, and therefore the best for determining the lift-off length [23, 24]. Although soot radiation could also be contributing to the recorded signal in the images, previous studies in the literature [23] also indicate that there should exist a spatial separation in both contributions. Therefore, while the downstream radiation will most probably be dominated by soot, the most 
upstream one is assumed to be essentially related to $\mathrm{OH}^{*}$ chemiluminiscence.

Figure 4 shows an image of $\mathrm{OH}^{*}$ radiation. These images are similar in appearance to the broadband ones, but with different spectral information. Additionally, these images have been taken with a long exposure, from the start of combustion until the end of injection $(\approx 3000 \mu s)$; as opposed to the broadband radiation where the exposure times were much shorter $(\approx 20 \mu s)$. The field of view in this case is located closer to the injector, in order to be able to measure the lift-off length with an adequate resolution. The processing algorithm for $\mathrm{OH}^{*}$ images is similar, but lift-off length is calculated as the closest zone to the nozzle where flame can be found [23]. The algorithm divides the image in two parts (upper and lower in Figure 4), based on the injector axis, because the time averaged images show two bright bands of light corresponding to the $\mathrm{OH}^{*}$ chemiluminescence from the diffusion flame. Nevertheless, these bands do not imply that the combustion extends further on the edges of the spray, but instead, they correspond to line-of-sight averaging of the light from the flame [25, 26]. Carrying on with the processing, the values per row and side are added up so two curves Digital Level vs Axial Distance can be obtained. Finally, the lift-off is calculated as the average level between valley and first peak of each curve, as this gives the mean location of the turbulently fluctuating lift-off length [23].

A schematic of the optical arrangement is also shown in Figure 1. Due to the lack of available optical accesses, the camera has been placed next to the parabolic mirror and at a small angle in order to image the spray properly. A 16-bit Andor iStar ICCD intensified camera equipped with a 100mm focal length $\mathrm{f}=2 \mathrm{UV}$ objective (by Bernhard Halle Nachfolger GmbH) and a 310nm 
interference filter $(\mathrm{FWHM}=10 \mathrm{~nm})$ was used to eliminate any additional radiation such as the soot luminosity. Because of the quasi-steady nature of the diffusion flame only one image was recorded per injection event, with an exposure time of $3 \mathrm{~ms}$ starting $2 \mathrm{~ms}$ after $\mathrm{SoI}$ and pixel $/ \mathrm{mm}$ ratio of 5.85 leading to a field of view of $78 \mathrm{~mm}$.

\section{Test conditions}

Keeping in mind the objective of the present work, six different blends of $n$-heptane and iso-octane in increments of $20 \%$ have been used, including the pure components. The nomenclature of each blend is PRF\#, where the \# stands for the percentage in volume of iso-octane in the blend, being the rest $n$-heptane.

The so-called Spray A injector has been used; this is a standard within the Engine Combustion Network (ECN) group, which is an international collaboration among different research laboratories in the world [12]. The injector has a single-hole nozzle with a nominal diameter of $90 \mu \mathrm{m}$ (Serial No. 210675). Reference injection pressure, chamber density, temperature and oxygen mole fraction for Spray A are $150 \mathrm{MPa}, 22.8 \mathrm{~kg} / \mathrm{m}^{3}, 900 \mathrm{~K}$ and $15 \%$, respectively. The only difference of the present study compared to the standard Spray A is the use of $n$-heptane/iso-octane blends, instead of the standard $n$-dodecane. As previously described, the reactive spray has been characterized in terms of spray tip penetration, lift-off length and soot radiation. Parametric variations of temperature and oxygen concentration have been performed as shown in Table 1. Additionally, for some experimental conditions (Table 2) the study was also carried out in an inert atmosphere, 
i.e. with no oxygen in the ambient with the main purpose of having a reference for the comparison of spray tip evolution.

Figure 5 shows a sample of the scattering among repetitions based on the inert spray penetration, for each operation condition 15 repetitions were performed. It shows that all the values are within two standard deviations (blue lines), which should enclose approximately $95 \%$ of the values according to the two-sigma $(2 \sigma)$ rule of the Normal distribution. Since the tests have proven to be repetitive, the results shown throughout the rest of the section will only present the average values of all the repetitions (red line). For timeaveraged values such as lift-off lengths and ignition delay times, the error bars presented will also correspond to two standard deviations (95\%).

\section{Results}

\subsection{Analysis of the baseline case}

Figure 6] shows a sequence of half-images that describes the evolution of the vapour penetration throughout the whole injection event for the inert and reactive sprays. For this example Spray A nominal conditions and PRF0 fuel have been selected.

From the start of injection (SoI), the spray penetrates as a clearly defined shadow under inert and reactive conditions. At around $500 \mu$ s after SoI, the tip of the reactive spray starts becoming transparent, this is due to the low temperature pre-reactions (also known as "cool flames") that precede the start of high temperature heat release. Such reactions result in the spray having similar refraction index as the surrounding air, and therefore becoming transparent [16, 27]. At $750 \mu$ s after SoI, the spray tip of the reactive 
spray becomes visible again, even though some parts are still transparent; also a widening of the spray tip is evident, this indicates that the ignition has begun as the premixed combustion of the air-fuel mixture has caused a sudden increase in the spray volume due to the lower density of the products from the high temperature reactions taking place. After $1000 \mu$ s, the whole reactive spray shadow is visible again.

The reactive spray is narrow in the non-reacting region, closer to the nozzle and up to the lift-off length; after this point its width increases abruptly due to combustion, which expands the original flow as explained in the previous paragraph. This difference can clearly be seen by comparing the shapes of the inert and reactive sprays after the ignition has taken place and the spray is fully visible again $(1500 \mu \mathrm{s})$. The inert spray maintains a constant angle and a steadily increasing radius all the way to the transient tip, while the reactive one is very similar to the inert up to the lift-off length (which is $23 \mathrm{~mm}$ for the present operating conditions), then the radius increases suddenly and the heat release region extends up to the spray tip. The combustion also causes the tip of the reactive spray to accelerate and penetrate at a faster rate than its inert counterpart, which can be observed on the images from $1500 \mu \mathrm{s}$ onwards. This means that the subsequent spray evolution is also governed by the combustion process. The reactive spray structure remains similar until the end of injection, with the spray tip penetrating steadily with time.

Figure 7 shows the broadband radiation images corresponding to the same spray evolution sequence, broadband luminosity is an indicator of the presence of soot in a reactive spray. At around $1000 \mu$ s after SoI combustion 
has already started, as explained in the previous paragraph. However, soot is not visible yet up to this time, either due to the low flame temperature or because not enough soot is formed yet. After $1500 \mu$ s from the SoI, soot starts to become visible at the tip of the spray; and as the spray keeps on penetrating further, the sooting region also grows axially. Nevertheless, the soot region widths are narrower than those of the spray due to the fact that schlieren marks the whole spray region, while soot radiation mainly occurs within the stoichiometric diffusion flame front [25].

Figure 8 (top) shows the average spray tip penetration for inert and reactive conditions and the flame length and soot onset length measured from image sequences such as the ones shown in Figures 2 and 3. From Figure 8 (top), it can be seen that the measured inert and reactive penetrations are close to one another until autoignition. Looking back at the $500 \mu$ s image in Figure 6, corresponding to the cool flame period, one can already discern some differences, which become evident after the high-temperature start of combustion at $666 \mu \mathrm{s}$. After this point, the reactive spray enters the acceleration phase and its penetration separates from the the inert case. This can be appreciated in Figure 8 (bottom), where the ratio between the reacting and inert penetration gas been plotted. This variable has a peak at the SoC, it decreases slightly and then starts increasing steadily until it reaches a maximum value and stabilizes under the given conditions. Although for this nominal case the stabilized maximum is found close to the end of the observation window, the parametric variations of ambient temperature and oxygen in the following sections will show a similar behaviour, with a first well defined acceleration followed by a second more stable period. This means 
that after the acceleration period of the reactive spray has ended, the ratio between reactive/inert velocities is approximately constant and no longer increasing [28].

As explained earlier, the sooting region of the spray tends to reach a steady value after a certain time. This can be seen in Figure 8 (top), where the soot onset length (SOL) reaches a constant value fairly quickly while the flame length (FL) keeps on penetrating along with the vapour until it starts deviating to come to a steady length which under this nominal condition occurs close to $4000 \mu \mathrm{s}$. Although this is close to the end of the observation window, the subequent study of this FL under oxygen concentration variation (Figure 16) will confirm that also for the present nominal condition stabilization occurs.

The $\mathrm{OH}^{*}$ lift-off length (LoL) is also shown in Figure 8 (top), but unlike the other parameters shown, this value is not time resolved as explained in Section 2. A remark worth to be made is the difference between the LoL and SOL, while both parameters measure the position of the flame, their spectral information is different. The broadband luminosity comes from the radiation of the soot, as opposed to the chemiluminescence of the $\mathrm{OH}^{*}$ radical. This latter value is the best indicative that combustion is taking place within a spray and is always present. The soot, on the other hand, depends strongly on the conditions and fuel used, and may not be present even if the spray is burning.

Summarizing, the reactive spray evolution can be broken down into four well defined stages. First, there is no combustion and its behaviour is like an inert spray $(0-250 \mu \mathrm{s})$. Second, pre-reactions start taking place, the spray 
becomes transparent due to the changes in density, broadband radiation is not visible due to low temperatures or not enough soot formed $(250-500 \mu \mathrm{s})$. Third, (500-2500 $\mathrm{s}$ ) high temperature ignition happens. In a first moment, the spray expands radially but not axially, but this is followed by the acceleration of the spray tip velocity compared to the inert case. Soot becomes visible, if conditions are adequate, SOL starts rising and so does the flame front. Fourth and last, the acceleration phase of the reacting case compared to the inert one ends, and the spray reaches a quasi-steady period where, its tip speed is similar to its inert counterpart $(2500-4000 \mu \mathrm{s})$. This four stages are consistent with observations of the authors in previous studies [28].

\subsection{Spray tip penetration}

Air temperature has no effect at all on the non-reacting part of the spray under reactive conditions, the density has kept at a constant value by adjusting the ambient pressure. This can be seen in Figure 9 (top) where all penetration curves overlap the inert one up to $600 \mu$ s approximately. At this point all reactive curves separate from the inert reference due to the prereactions occurring at the spray front, this is shown more clearly in Figure 9 (bottom) where the ratio between reactive and inert penetrations is depicted. Once the ignition has taken place, the reactive spray will continue deviating from the inert case at a higher rate during the acceleration phase; but when it reaches the quasi-steady phase, the acceleration will cease and the ratio between Reactive/Inert penetration will remain constant. It can be seen that the higher the temperature of the air, the sooner the acceleration period will begin and, therefore, the stabilization period will be reached earlier as the combustion is faster. As mentioned earlier, the temperature does not have 
an effect on the non-reacting region, but will affect the ignition delay time and hence the point at which the acceleration of the tip commences. Concurrently, Figure 9 (top) shows that the higher air temperature causes the lift-off length to become shorter for the same injection pressure.

The oxygen concentration has an effect on the start of combustion of a spray and it doesn't affect the mixing or evaporation of the non-reactive phase. Figure 10 shows the comparison of the penetrations under the parametric variation of oxygen. It can be seen that not only the reactivity of the air causes the curves to depart at different positions, but the more pronounced slopes as the oxygen fraction increases is an indicator of a combustion happening more aggressively. Estimations of adiabatic flame temperature for a stoichiometric mixture, initially at the adiabatic mixing conditions, indicate that it changes from around $2337 \mathrm{~K}$ for the lowest oxygen case to $2524 \mathrm{~K}$ and $2681 \mathrm{~K}$ for the medium and highest cases. This approximate $350 \mathrm{~K}$ temperature variation with oxygen is much stronger than that observed when changing the ambient air temperature, 2256, 2337 and $2405 \mathrm{~K}$ for the 800, 900 and $1000 K$ cases shown in Figure 9. Therefore it can be hypothesized that the corresponding acceleration of the reacting vs. the inert case is dependent on the combustion-induced temperature variation, which will create a corresponding density drop. Finally, Figure 10 (top), also shows the lift-off length to be shorter as the oxygen increases, this proves that the increased reactivity of the mixture is shifting the reactive region of the spray closer to the nozzle.

The fuel effect on the reactive penetration is very similar to that of the oxygen, because it will modify the reactivity of the mixture. The fuel has 
very little effect on the inert spray [29, 30]; on the other hand, the reactive penetration shows a strong dependency on the fuel due to different ignition delay times. Figure 11 (top) shows the penetration of the baseline case for all fuels and the inert penetration of PRF0 as a reference point. It can be seen that as the percentage of iso-octane increases (higher PRF), the penetration starts deviating form the inert case at a later time and with a less pronounced slope, and for some cases it doesn't seem to separate at all. This last phenomenon could be due to two factors, either the ignition takes place much later than the time window studied, or because it doesn't occur at all. This also explains why the stabilized penetrations for all fuels do not converge on the same values. Figure 11 (bottom) shows the penetration ratios for all PRFs. In a similar trend to that of the oxygen, being that a more reactive mixture will cause the curve to deviate earlier and faster, not all curves start deviating, meaning that the ignition has not been achieved yet. Moreover, the blends that burn do not seem to reach the same steady value. Finally, the effect of the fuel on the lift-off length can be appreciated in Figure 11 (top), where the lower the percentage of $n$-heptane (lower PRF) the longer the lift-off length is. This is analogue with increasing the air temperature or the oxygen concentration, which results in a more reactive mixture and hence a shorter lift-off length.

The previous results also help at the understanding of lift-off stabilization mechanism. Although originally thought as based upon a flame front velocity balance, extensive evidences starting from [31] indicate that lift-off stabilizes based upon the autoignition of fuel elements being injected. In this particular case, the fuel composition has been swept from $n$-heptane to iso- 
octane, both of which have very similar laminar flame speeds [32] but highly different autoignition properties. From a point of view of flame stabilization by velocity equilibrium, both fuels should produce the same lift-off length. However, experimental results presented here confirm that both lift-off and autoignition delay change with operating conditions in a highly similar fashion, which indicates the leading role of autoignition on lift-off stabilization.

\subsection{Ignition delay}

During the study of the penetration it was observed that some parameters had a stronger effect on the ignition delay. This was seen where the Reactive/Inert penetration ratio started deviating from unity. In this subsection, the analysis of the ignition delay time under the parametric variations (Table 1) is presented.

The oxygen concentration appears to have an effect on the start of combustion. This is because while the same amount of air is being entrained, more oxygen is available, leading to a more reactive air-fuel mixture, so the ignition can happen sooner 33]. Figure 12 shows the effect of varying the oxygen concentration for each blend tested. Altering the fuel reactivity and the oxygen concentration at the same time has a combined effect, where the higher PRF (more iso-octane) causes the differences in ignition delay to be greater among oxygen concentrations. As mentioned previously, this combined effect is related to the reactivity of the air-fuel mixture and it seems to have a non-linear trend.

Air temperature has the strongest effect on the ignition delay than any of the other parameters. Figure 13 shows that the difference among 950K and $900 \mathrm{~K}$ is smaller (around $200 \mu$ s for PRF20) compared to the effect of 
reducing the temperature from $900 \mathrm{~K}$ to $800 \mathrm{~K}$ (approx. $1000 \mu \mathrm{s}$ for PRF0). The explanation for this non-linear effect is that at low temperatures the rate of chemical reaction is slow enough to ignore the time required to form the ignitable mixture, while at high temperatures the ignition delay chemistry progresses very fast, and delay is mainly dominated by physical processes 34]. Missing points for the low temperature cases for PRF60 to PRF100, as well as the intermediate temperature for PRF100 are due to combustion not occurring within the investigated conditions. Additionally, it can be seen that the difference in ignition delay between $15 \%$ and $18 \%$ of oxygen is similar to changing the temperature from $900 \mathrm{~K}$ to $950 \mathrm{~K}$ for PRF20.

\subsection{Flame lift-off length}

As was also seen during the analysis of the penetration, the boundary conditions not only affected the time at which the reactive curve started deviating from the inert one (ignition delay time), but also on the flame lift-off length, which will be analyzed in the present section.

The lift-off length seems to be dramatically affected by changes in the air temperature. This is very clear to see in Figure 14, where the lower the temperature the longer the lift-off length is going to be [23, 33, 35, 36, 31], but more important is that the effect is non-linear. A statistical regression fitting of the results shown in Figure 14 indicates that the temperature dependence of the lift-off length occurs with an exponent of $-4.27,-4.57,-4.84$ and -5.28 for PRF0 to PRF60, which indicates that the higher the fuel reactivity, the more important the temperature dependence is. The fitted lines are also presented in Figure 14 as dashed lines along with the expressions. Compared to a reference work in [31, with a temperature dependence of -3.74 , the 
temperature sensitivity is higher for all cases in the present study. However, the present results are coherent with previous results obtained in the same experimental facility $(-5.0$ to -5.4 as reported in [21]).

The oxygen concentration causes a similar effect to that of the air temperature. Figure 15 shows that the higher the oxygen concentration, the shorter the lift-off length is due to the higher reactivity of the mixture causing the spray to burn earlier (shorter ignition delay) and since the velocity of the spray is not altered (same injection pressure), this happens closer to the injector [23, 35].

Figures 14 and 15 also shows the effect of the fuel composition, and it can be seen that it has a strong effect on the lift-off length. Like it was mentioned earlier, the percentage of iso-octane on the blend reduces the reactivity of the mixture tremendously, especially when the percentage is over 50. Moreover, the results shown only present values up to PRF80, due to the fact that the camera setup recorded the $\mathrm{OH}^{*}$ chemiluminescence in a fixed temporal window, and greater stabilization times of the lift-off length were not able to be registered. Additionally, some conditions were not favourable for the ignition of PRF100 such as $800 \mathrm{~K}$ and $900 \mathrm{~K}$ at $15 \%$ oxygen. In a similar way as the effect on the ignition delay, the effects between $15 \%$ and $18 \%$ of oxygen are similar to changing the temperature from $900 \mathrm{~K}$ to $950 \mathrm{~K}$.

\subsection{Stabilized flame length}

The length of the flame was measured by means of broadband radiation, but stabilized values are not achieved for all operating conditions due to either spatial or temporal limitations in the acquisition setup.

Radiation onset occurs after ignition delay. If resulting radiation is strong 
enough to be detected, measured flame penetration is similar to that of the reacting spray tip penetration. Figure 16 shows the evolution of the flame penetration under the oxygen concentration variation. For all three cases it can be seen that the flame penetrates faster than the corresponding spray tip of the non-reacting references. Also, and according to what was seen in the study of the spray penetration, the deviation of the flame penetration occurs earlier and more aggressively as the oxygen concentration increases. Finally, the higher concentration of oxygen also causes the flame to stabilize closer to the nozzle. The reason for this behaviour is that the more reactive the air-fuel mixture the closer the stoichiometric surface will be to the injector, resulting in a shorter stabilized flame length.

Stabilized flame length measurements under Diesel engine conditions are rarely available in the literature, mainly due to the length, which is usually larger than most optical accesses, and the time needed for stabilization, which is quite long in terms of engine scales. Comparable results to the ones shown here are those reported in [37, which use long-exposure $\mathrm{OH}^{*}$ chemiluminescence images to quantify the stabilized FL for different nozzle diameters. To compare the present results with those measurements, the obtained FL values have been normalized for the different experimental conditions according to the following scaling law based on a momentum-controlled diffusion flame description:

$$
F L_{n o r m}=F L \cdot \frac{z_{s t}}{d_{0} \cdot \sqrt{\frac{\rho_{f}}{\rho_{a}}} \cdot \sqrt{\frac{\rho_{a}}{\rho_{s t, r}}}}
$$

where $d_{e q}=d_{0} \cdot \sqrt{\frac{\rho_{f}}{\rho_{a}}}$ is the equivalent diameter, which was already used 
for the normalization under inert conditions, $z_{s t}$ is the stoichiometric mixture fraction, and $\sqrt{\frac{\rho_{a}}{\rho_{s t, r}}}$ is a term that accounts for entrainment reduction due to the combustion-induced density decrease, where $\rho_{s t, r}$ is the stoichiometric mixture density under reacting conditions. This term has been demonstrated to justify entrainment decrease under atmospheric pressure gas flames [38]. Figure 17 presents the results of the normalized flame length $\left(F L_{\text {norm }}\right)$, which shows the values to be in the range of 4-6 for most operating conditions, in agreement with those from [37]. Therefore, it confirms that the stabilization of the diffusion flame is controlled by mixing arguments, and not by fuel reactivity.

\section{Conclusions}

The conclusions drawn from this investigation are as follows:

- The ambient temperature and oxygen concentration have very similar effects. They have no apparent effect on spray penetration during the inert spray evolution, but they do have an effect on the reacting spray evolution. As temperature rises or oxygen concentration increases, the reactivity of the mixture increases dramatically, so the fuel will start to burn earlier and closer to the nozzle, resulting in shorter ignition delay times and lift-off lengths. Where they have different effects is on the stabilized flame lengths, as a higher oxygen concentration will results in shorter lengths while the temperature does not have an effect on the stabilized flame. Finally, even though they have no effect on the inert vapour penetration, the shorter ignition delay times will cause the 
start of the acceleration phase to start sooner and its slope to be more pronounced, therefore resulting in longer penetrations.

- Increasing the amount of iso-octane in the mixture has a completely opposite effect on the combustion behaviour in comparison to increasing oxygen content or temperature in the air. As iso-octane is less reactive than $n$-heptane, increasing its concentration will only cause the mixture to start to burn later and further away from the injector tip. Even though iso-octane has a slightly higher sooting tendency than $n$-heptane, the increase in lift-off causes much leaner mixtures, resulting in lower soot formation and a concurrent decrease in broadband radiation intensity. Two trends are defined regarding the octane number of the blend. On one hand, for the lower half of the octane scale (PRF0-20-40) the reactivity of the mixture (lift-off lengths and ignition delay times) decreases linearly with the fuel proportion, while on the the upper half (PRF60-80-100) a non linear trend can be seen.

A scaling law for the stabilized flame lenght based on momentum-controlled considerations has been validated for those conditions where such stabilization occurs. This scaling law agrees with similar results in the literature.

Finally, a small projection on the applicability of the present results for engine performance will be made. For that purpose, ignition delay and liftoff results (Figures 12 and 15) for PRF0 with $15 \%$ of oxygen and PRF40 with $21 \%$ of oxygen will be revisited. They could be taken as representative of a Diesel engine running with pure Diesel and an EGR level of $30 \%$ for a high load case, or with a Diesel-gasoline blend and no EGR. One can see that both cases have an ignition delay time of $600 \mu$ s and approximately 
the same lift-off length, $23 \mathrm{~mm}$ and $22 \mathrm{~mm}$. This would mean a similar combustion timing for both fuels, which is always interesting in terms of engine calibration. Furthermore, due to the higher oxygen amount in ambient air, the equivalence ratio at the lift-off for the gasoline (PRF40) would be much leaner, which should result in lower soot formation within the flame, and therefore lower exhaust particulates. The aforementioned comparisons agree with general trends presented in recent studies using primary reference fuels and similar strategies to reduce emissions while maintaining engine performance [2, 7, 39, 40, 41, 42, 43, 44, 45, 46, 47, 48. Nevertheless, further research on this topic is needed, to confirm the previous conclusion.

\section{Acknowledgments}

Authors acknowledge that part of this work was performed in the frame of Project DUFUEL TRA2011-26359, funded by the Spanish Government. Also, authors would like to thank the Pontificia Universidad Católica del Perú for financing the first year of studies of W.Vera-Tudela and making it possible for him to start his program of Ph.D. at the Universitat Politècnica de València.

[1] R. Hanson, S. Kokjohn, D. Splitter, R. Reitz, An experimental investigation of fuel reactivity controlled pcci combustion in a heavy-duty engine, SAE Technical Paper (2010-01-0864).

[2] G. Kalghatgi, R. K. Gurubaran, A. Davenport, A. Harrison, Y. Hardalupas, A. Taylor, Some advantages and challenges of running a euro iv, v6 diesel engine on a gasoline fuel, Fuel 108 (2013) 197-207. 
[3] J. Benajes, S. Molina, A. García, J. Monsalve-Serrano, Effects of direct injection timing and blending ratio on rcci combustion with different low reactivity fuels, Energy Conversion and Management 99 (2015) 193-209.

[4] J. Desantes, J. Benajes, A. García, J. Monsalve-Serrano, The role of the in-cylinder gas temperature and oxygen concentration over low load reactivity controlled compression ignition combustion efficiency, Energy 78 (2014) 854-868.

[5] W. Han, C. Yao, Research on high cetane and hig octane number fuels and the mechanism for their common oxidation and auto-ignition, Fuel 150 (2015) 29-40.

[6] H. Machrafi, S. Cavadia, P. Gilbert, An experimental and numerical analysis of the hcci aiuto-ignition process of primary reference fuels, toluene reference fuels and diesel fuels in an engine, varying the engine parameters, Fuel Processing Technology 89 (2008) 1007-1016.

[7] X. Lü, W. Chen, Y. Hou, Z. Huang, Study on the ignition, combustion and emissions of a hcci combustion engines fueled with primary reference fuels, SAE Technical Paper (2005-01-0155).

[8] Q. Xionq, K. Inaba, H. Ogawa, G. Shibata, Influence of fuel properties on opoperation range and thermal efficiency of premixed diesel combustion, SAE International Journal of Fuels and Lubricants 6(3) (2013-329054) (2013) 1005-1013.

[9] J. López, J. García-Oliver, A. García, V. Domenech, Gasoline effects on spray characteristics, mixing and auto-ignition processes in a ci en- 
gine under partially premixed combustion conditions, Applied Thermal Engineering 70(1) (2014) 996-1006.

[10] B. Knox, C. Genzale, L. Pickett, J. García-Oliver, W. Vera-Tudela, Combustion recession after end of injection in diesel sprays, SAE International Journal of Engines 8(2) (2015-01-0797).

[11] H. Persson, O. Andersson, R. Egnell, Fuel effects on flame lift-off under diesel conditions, Combustion and Flame 158 (2011) 91-97.

[12] L. Pickett, C. Genzale, G. Bruneaux, L. Malbec, L. Hermant, C. Christiansen, J. Schramm, Comparison of diesel spray combustion in different high-temperature, high-pressure facilities., SAE International Journal of Engines 3(2) (2010-01-2106) (2010) 156-181.

[13] R. Baert, P. Frijters, B. Somers, C. Luijten, W. de Boer, Design and operation of a high pressure, high temperature cell for hd diesel spray diagnostics: Guidelines and results, SAE Technical Paper (2009-01-0649).

[14] R. Payri, J. García-Oliver, M. Bardi, J. Manin, Fuel temperature influence on diesel sprays in inert and reacting conditions, Applied Thermal Engineering 35 (2012) 185-195.

[15] G. Settles, Schlieren and Shadowgraph Techniques: Visualizing Phenomena in Transparent Media, Springer-Verlag, Berlin, Germany, 2001.

[16] L. Pickett, S. Kook., T. Williams, Visualization of diesel spray penetration, cool-flame, ignition, high-temperature combustion, and soot formation using high-speed imaging, SAE International Journal of Engines 2(1) (2009-01-0658) (2009) 439-459. 
[17] J. Naber, D. Siebers, Effects of gas density and vaporization on penetration and dispersion of diesel sprays, SAE Technical Paper (960034).

[18] Engine Combustion Network, http://www.sandia.gov/ecn/index.php.

[19] L. Pickett, J. Manin, C. Genzale, D. Siebers, M. Musculus, C. Idicheria, Relationship between diesel fuel spray vapor penetration/dispersion and local fuel mixture fraction, SAE International Journal of Engines 4(1) (2011-01-0686) (2011) 764-799.

[20] J. Pastor, R. Payri, J. García-Oliver, J. Nerva, Schlieren measurements of the ecn-spray a penetration under inert and reacting conditions, SAE Technical Paper (2012-01-0456).

[21] J. Pastor, R. Payri, J. García-Oliver, F. Briceo, Schlieren methodology for the analysis of transient diesel flame evolution, SAE International Journal of Engines 6(3) (2013-24-0041) (2013) 1661-1676.

[22] M. Bardi, R. Payri, L. Malbec, G. Bruneaux, L. Pickett, J. Manin, T. Bazyn, C. Genzale, Engine combustion network: Comparison of spray development, vaporization, and combustion in different combustion vessels, Atomization and Sprays 22(10) (2012) 807-842.

[23] B. Higgins, D. Siebers, Measurement of the flame lift-off location on di diesel sprays using oh chemiluminescence, SAE Technical Paper (200101-0918).

[24] A. Gaydon, The Spectroscopy of Flames, Chapman and Hall, 1974. 
[25] J. Dec, A conceptual model of di diesel combustion based on laser-sheet imaging, SAE Technical Paper (970873).

[26] H. Kosaka, T. Nishigaki, T. Kamimoto, T. Sano, A. Matsutani, S. Harada, Simultaneous 2-d imaging of oh radicals and soot in a diesel flame by laser sheet techniques, SAE Technical Paper (960834).

[27] S. Skeen, J. Manin, L. Pickett, Simultaneous formaldehyde plif and highspeed schlieren imaging for ignition visualization in high-pressure spray flames, Proceedings of the Combustion Institute 35(3) (2015) 3167-3174.

[28] J. Desantes, J. Pastor, J. García-Oliver, F. Briceo, An experimental analysis on the evolution of the transient tip penetration in reacting diesel sprays, Combustion and Flame 161(8) (2014) 2137-2150.

[29] S. Möller, G. Dutzler, P. Priesching, J. Pastor, C. Micó, Multicomponent modeling of diesel fuel for injection and combustion simulation, SAE Technical Paper (2013-24-0007).

[30] S. Kook, L. Pickett, Liquid length and vapor penetration of conventional, fischer-tropsch, coal-derived, and surrogate fuel sprays at hightemperature and high-pressure ambient conditions, Fuel 93 (2012) 539548.

[31] L. Pickett, D. Siebers, C. Idicheria, Relationship between ignition processes and the lift-off length of diesel fuel jets, SAE Technical Paper (2005-01-3843).

[32] J. van Lipzig, E. Nilsson, L. de Goey, A. Konnov, Laminar burning 
velocities of n-heptane, iso-octane, ethanol and their binary and tertiary mixtures, Fuel 90 (2011) 2773-2781.

[33] L. Malbec, J. Egúsquiza, G. Bruneaux, M. Meijer, Characterization of a set of ecn spray a injectors: Nozzle to nozzle variations and effect of spray characteristics, SAE International Journal of Engines 6(3) (201324-0037) (2013) 1642-1660.

[34] T. Ito, M. Ueda, T. Matsumoto, T. Kitamura., J. Senda, H. Fujimoto, Effects of ambient gas conditions on ignition and combustion process of oxygenated fuel sprays, SAE Technical Paper (2003-01-1790).

[35] J. Benajes, R. Payri, M. Bardi, P. Martí-Aldaraví, Experimental characterization of diesel ignition and lift-off length using a single-hole ecn injector, Applied Thermal Engineering 58 (2013) 554-563.

[36] D. Siebers, B. Higgins, Flame lift-off on direct-injection diesel sprays under quiescent conditions, SAE Technical Paper (2001-01-0530).

[37] L. Pickett, D. Siebers, Orifice diameter effects on diesel fuel jet flame, Journal of Engineering for Gas Turbines and Power 127(1) (2005) 187196.

[38] D. Han, M. Mungal, Direct measurement of entrainment in reacting/nonreacting turbulent jets, Combustion and Flame 124(3) (2001) $370-386$.

[39] V. Manente, Gasoline partially premixed combustion - an advanced internal combustion engine concept aimed to high efficiency, low emissions 
and low acoustic noise in the whole load range, Ph.D. thesis, Lund Institute of Technology (2010).

[40] R. Reitz, High-efficiency fuel reactivity controlled compression ignition (rcci) combustion, in: 16th Directions in Engine-Efficiency and Emissions Research (DEER) Conference, Detroit, MI, Engine Research Center, University of Wisconsin-Madison, 2010.

[41] S. Kunte, A. Bertola, P. Obrecht, K. Boulouchos, Temporal soot evolution and diesel engine combustion: influence of fuel composition, injection parameters, and exhaust gas recirculation, International Journal of Engine Research 7 (2006) 459-470.

[42] M. Yao, B. Zhang, Z. Zheng, Z. Cheng, Y. Xing, Experimental study on the effects of egr and octane number of prf fuel on combustion and emission characeristics of hcci engines, SAE Technical Paper (2005-010174).

[43] L. Hildingsson, G. Kalghatgi, N. Tait, B. Johansson, A. Harrison, Fuel octane effects in the partially premixed combustion regime in compression ignition engines, SAE Technical Paper (2009-01-2648).

[44] R. Hanson, D. Splitter, R. Reitz, Operating a heavy-duty directinjection compression-ignition engine with gasoline for low emissions, SAE Technical Paper (2009-01-1442).

[45] P. Bessonette, C. Schleyer, K. Duffy, W. Hardy, M. Liechty, Effects of fuel property changes on heavy-duty hcci combustion, SAE Technical Paper (2007-01-0191). 
[46] G. Kalghatgi, P. Risberg, H. ngström, Advantages of fuels with high resistance to auto-ignition in late-injection, low-temperature, compression ignition combustion, SAE Technical Paper (2006-01-3385).

[47] G. Kalghatgi, P. Risberg, H. ngström, Partially pre-mixed auto-ignition of gasoline to attain low smoke and low nox at high load in a compression ignition engines and comparison with a diesel fuel, SAE Technical Paper (2007-01-0006).

[48] R. Reitz, R.Hanson, D. Splitter, S. Kokjohn, High-efficiency, ultralow emission combustion in a heavy-duty engine via fuel reactivity control, in: 15th Diesel Engine-Efficiency and Emissions Research (DEER) Conference, Dearborn, MI, Engine Research Center, University of Wisconsin-Madison, 2009. 


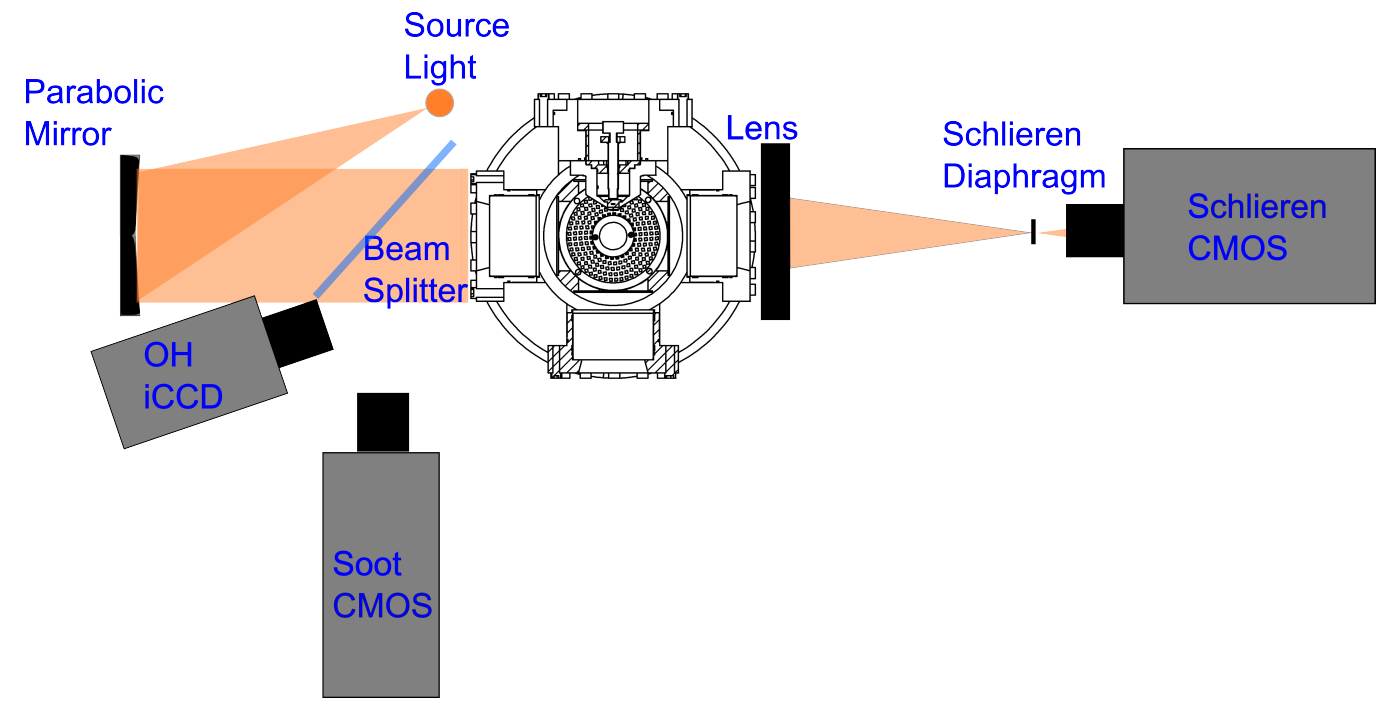

Figure 1: Schematic of the experimental setup for the study of the reactive spray 


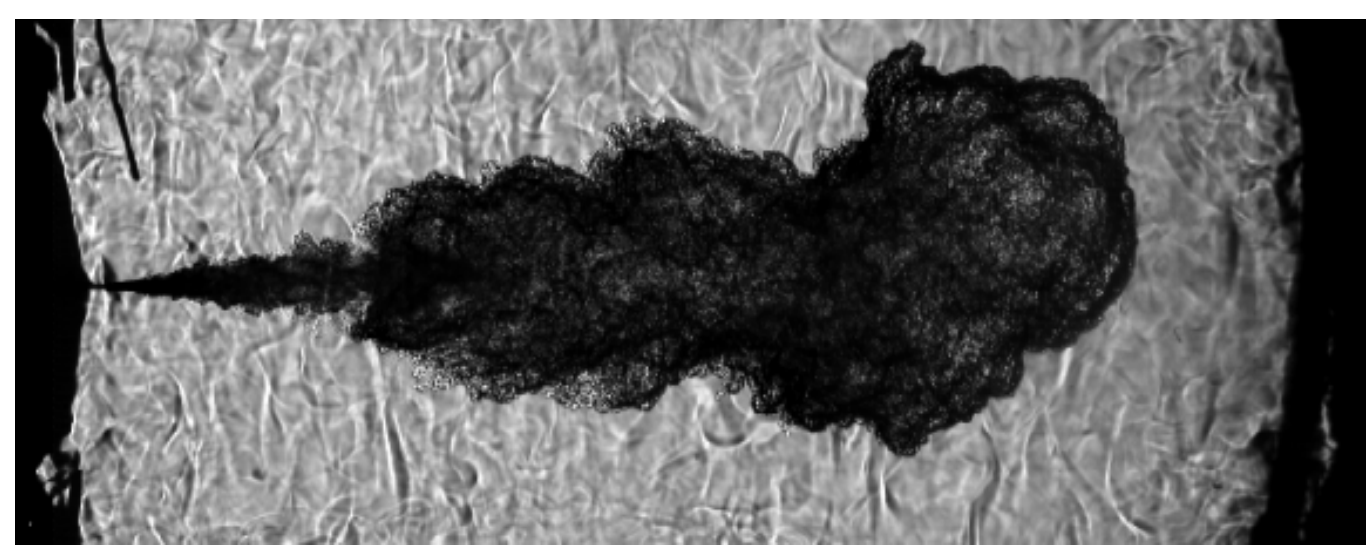

Figure 2: Sample image of the schlieren technique at $3000 \mu s$ after SoI 


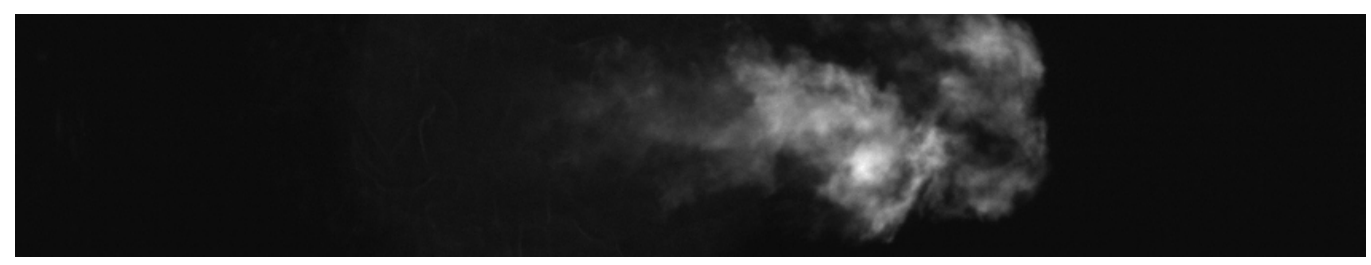

Figure 3: Sample of the broadband radiation imaging at 3000 $\mu$ s after SoI 


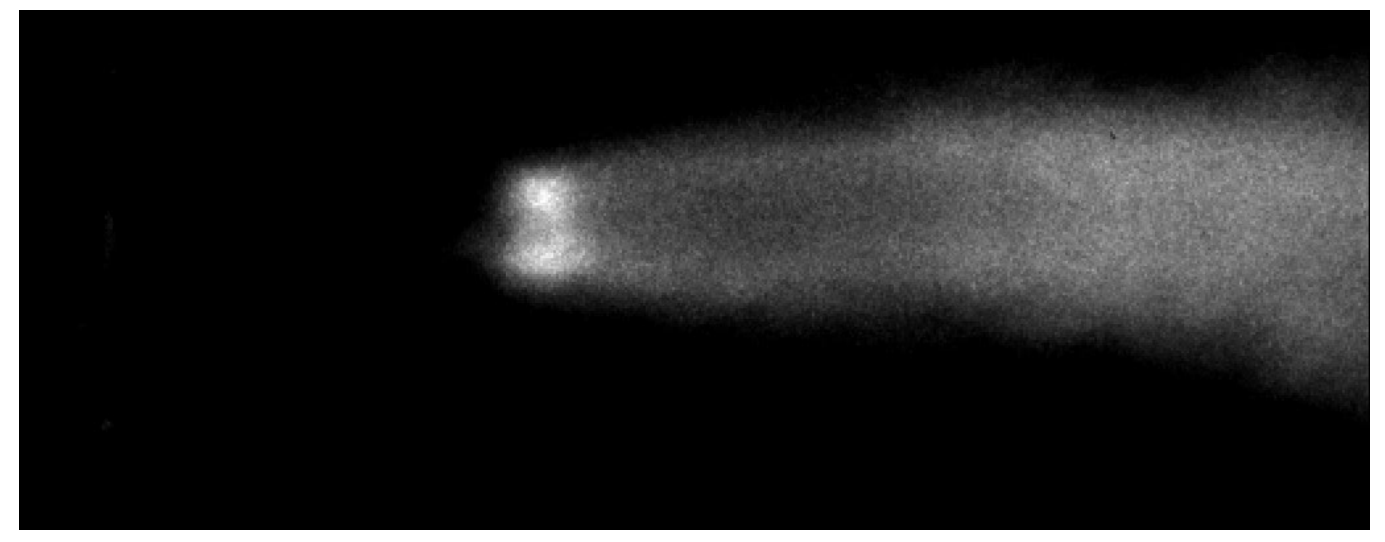

Figure 4: Sample image of the $\mathrm{OH}^{*}$ chemiluminescence technique from $2000 \mu \mathrm{s}$ to $5000 \mu \mathrm{s}$ after SoI 


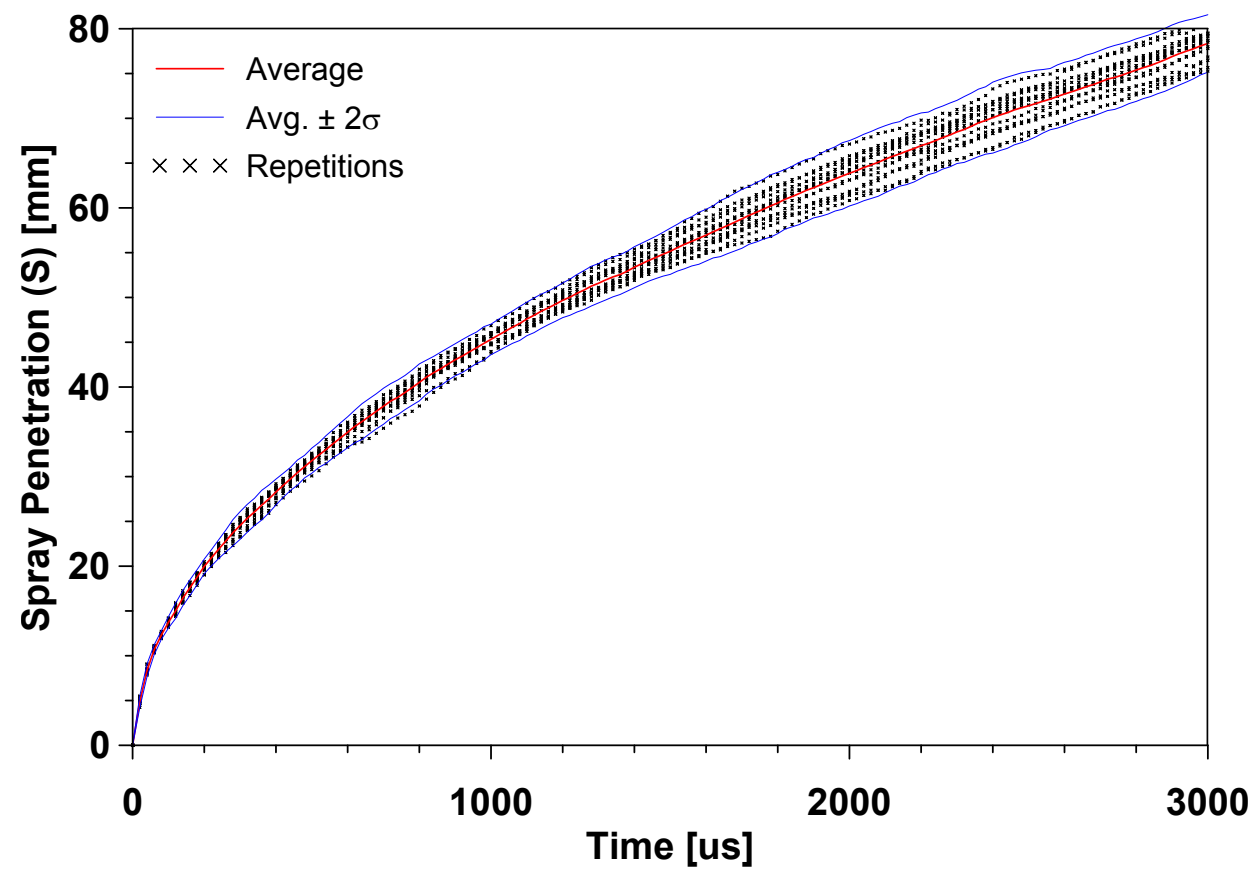

Figure 5: Spray penetration scattering of all 15 repetitions and average value, for PRF0 at $900 \mathrm{~K}, 15 \% \mathrm{O}_{2}$ and $150 \mathrm{MPa}$, time after SoI. 


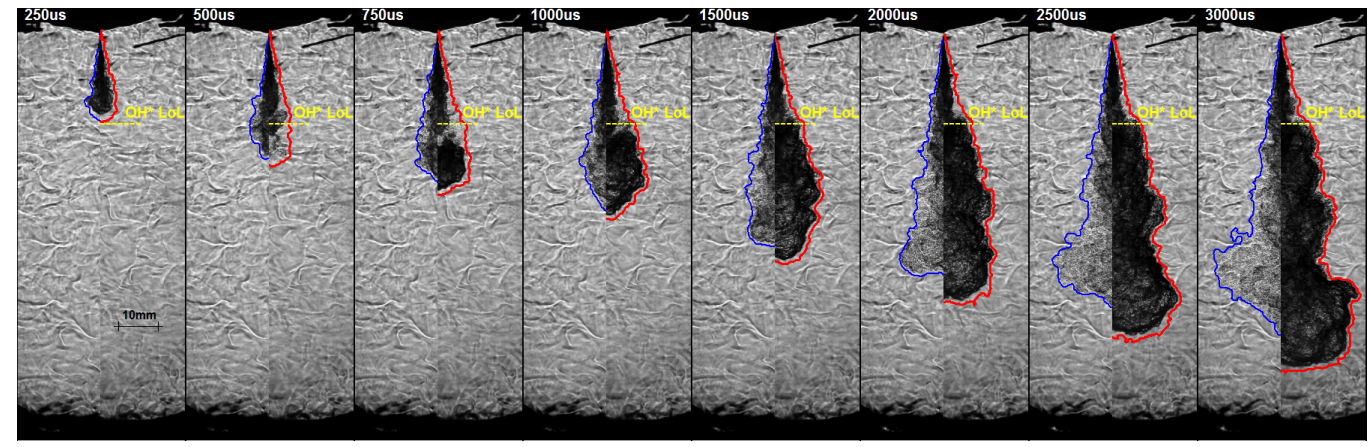

Figure 6: Evolution of inert (blue) and reactive (red) spray penetration for PRF0 at 900K, $15 \% \mathrm{O}_{2}$ and $150 \mathrm{MPa}$, time after SoI. 


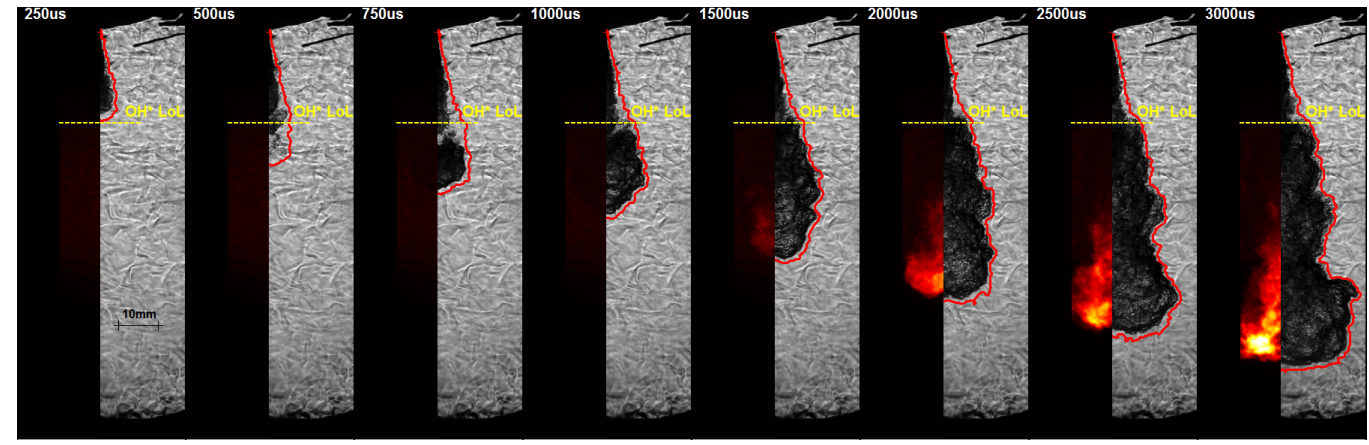

Figure 7: Evolution of soot luminosity and spray penetration simultaneous images for PRF0 at $900 \mathrm{~K}, 15 \% \mathrm{O}_{2}$ and $150 \mathrm{MPa}$, time after SoI. 


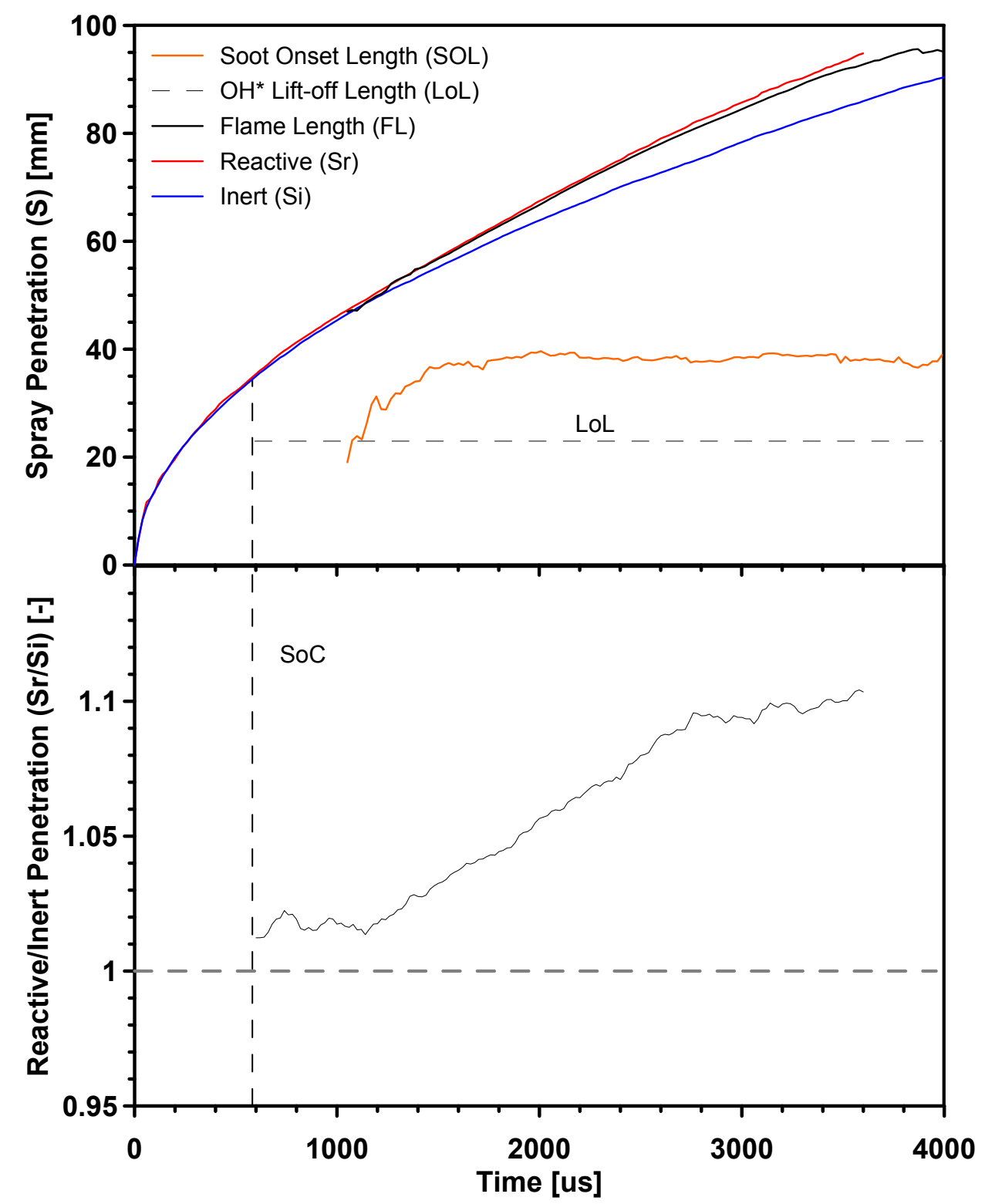

Figure 8: Time resolved evolution of the inert and reactive penetrations, along with flame length, soot onset length and lift-off length (top) and Reactive-Inert spray penetration ratio (bottom) for PRF0 at $900 \mathrm{~K}, 15 \% \mathrm{O}_{2}$ and $150 \mathrm{MPa}$, time after SoI. 


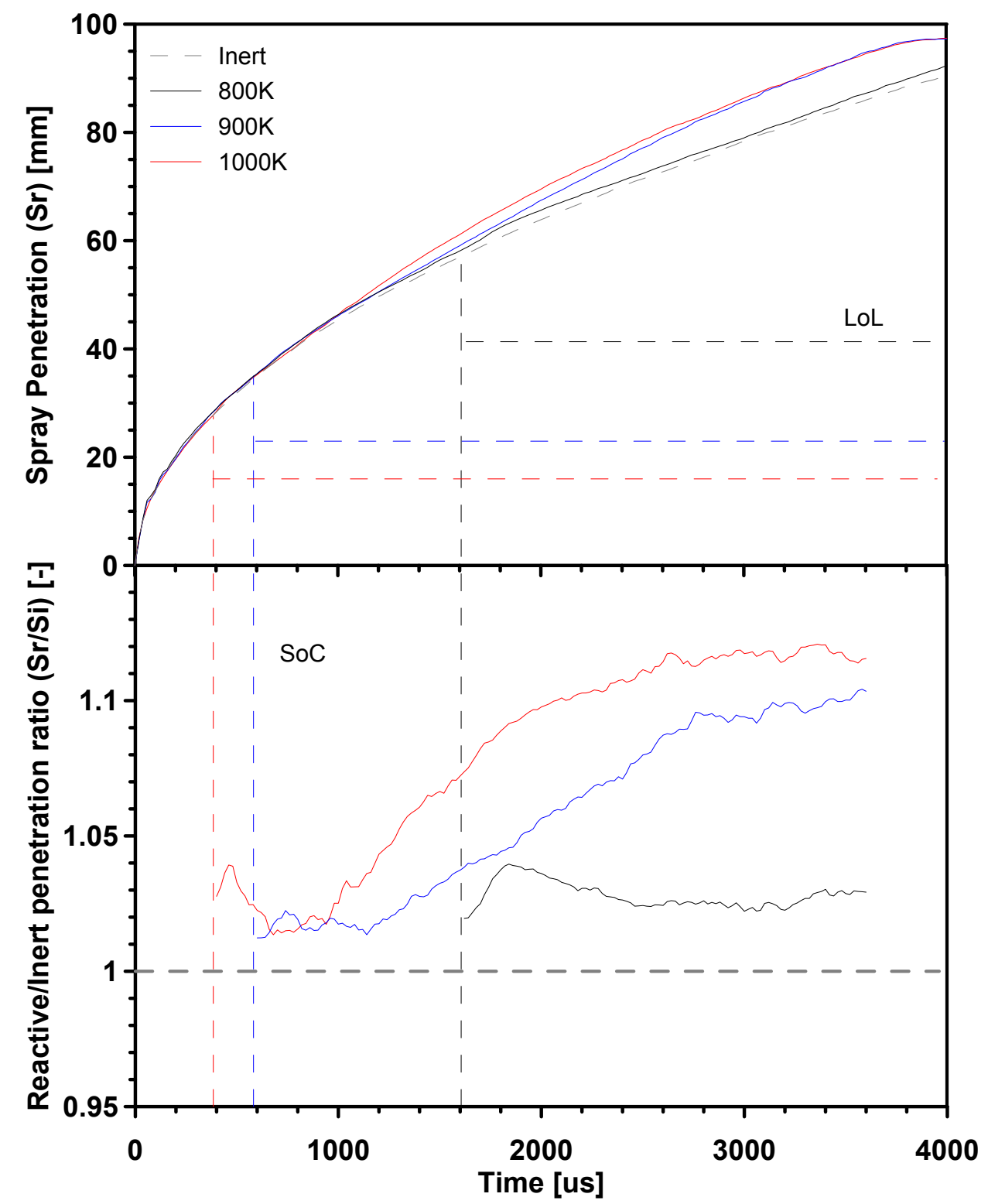

Figure 9: Reactive spray penetration (top) and Reactive/Inert spray penetration ratio (bottom) comparison for PRF0 under air temperature variation at $15 \% \mathrm{O}_{2}$, time after SoI. 


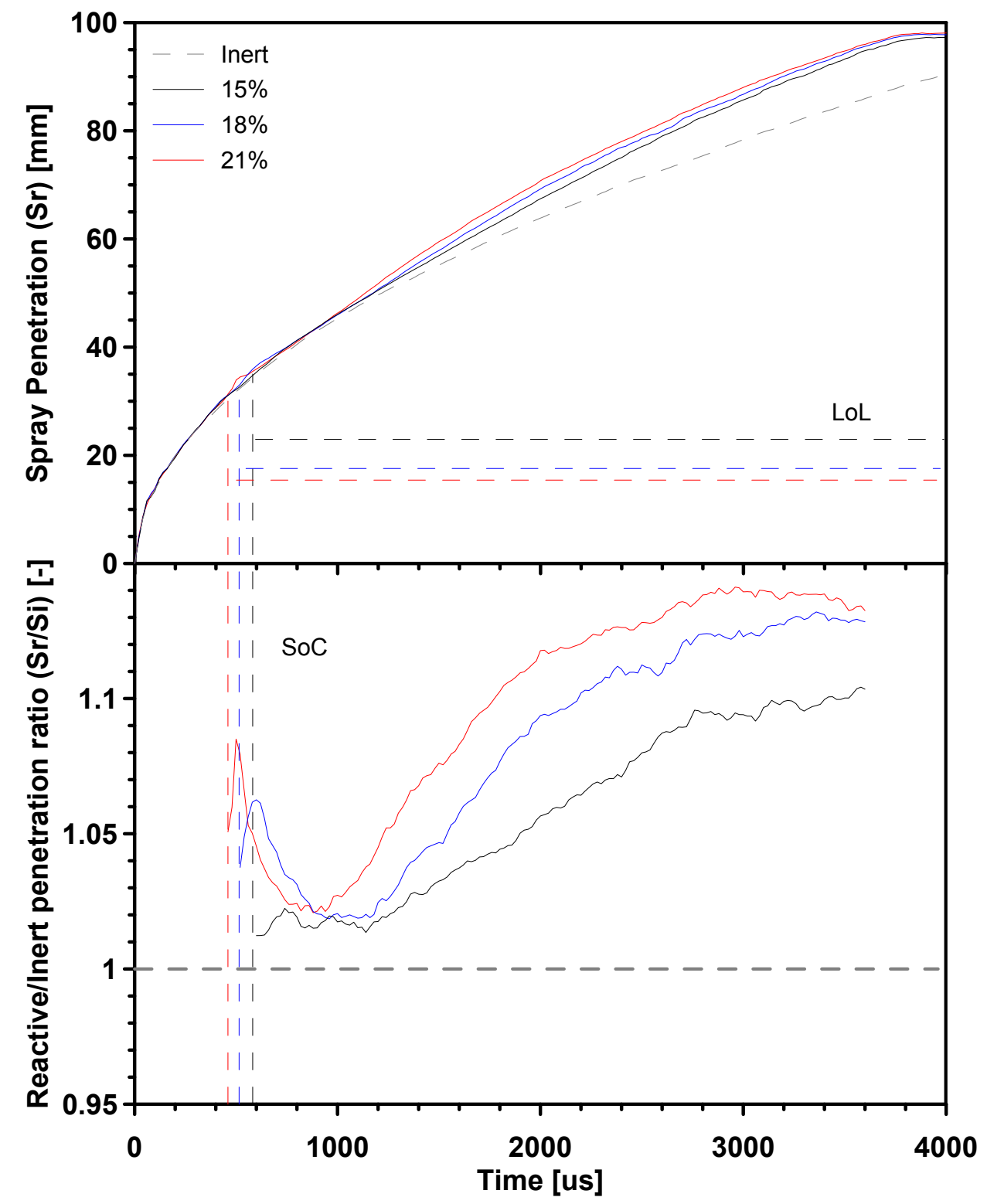

Figure 10: Reactive spray penetration (top) and Reactive/Inert spray penetration ratio (bottom) comparison for PRF0 under oxygen concentration variation at 900K, time after SoI. 


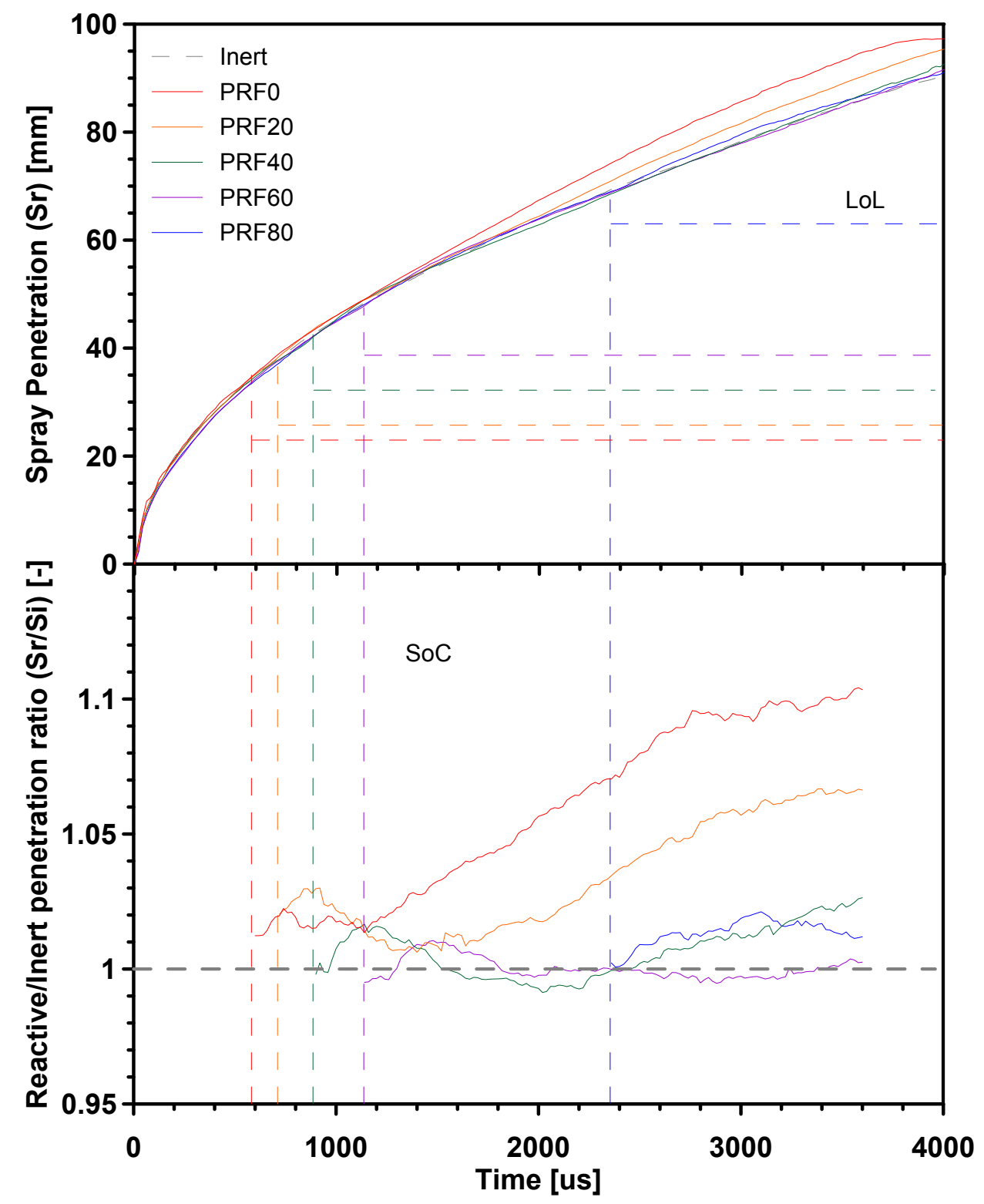

Figure 11: Reactive spray penetration (top) and Reactive/Inert spray penetration ratio (bottom) comparison for PRF0 to PRF100, at $900 \mathrm{~K}$ and $15 \% \mathrm{O}_{2}$, time after SoI. 


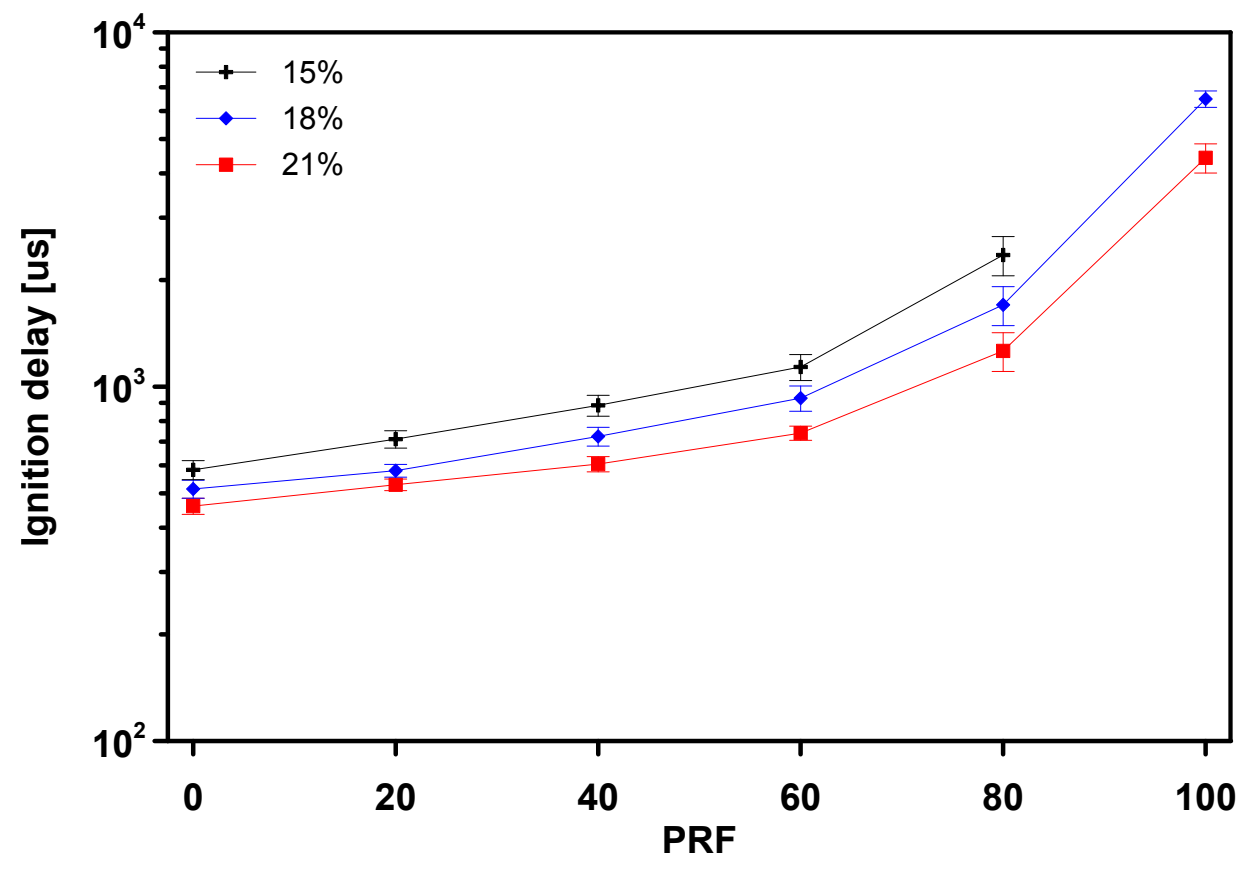

Figure 12: Ignition delay comparison under oxygen concentration variation, time after SoI 


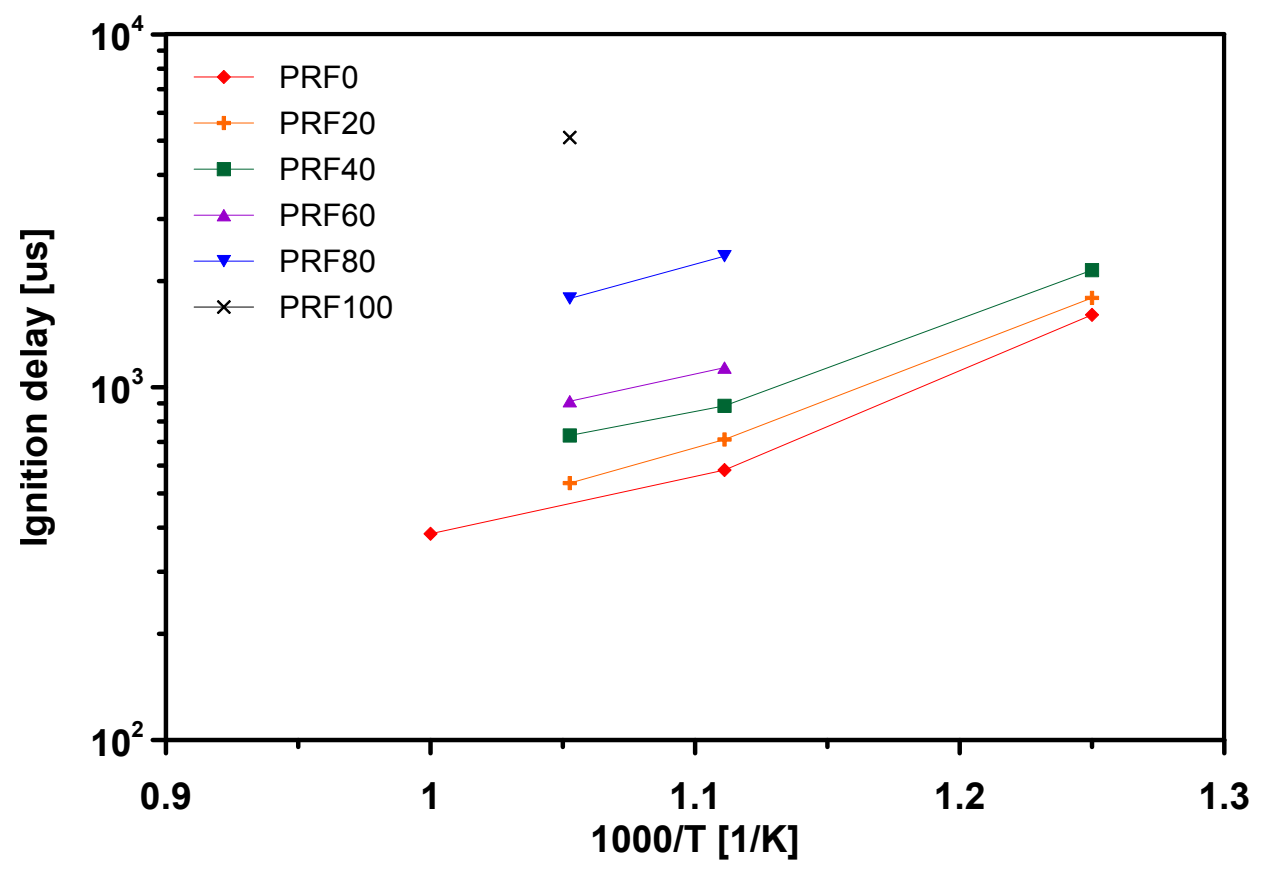

Figure 13: Ignition delay comparison under air temperature variation, time after SoI.Oxygen concentration $15 \%$ 


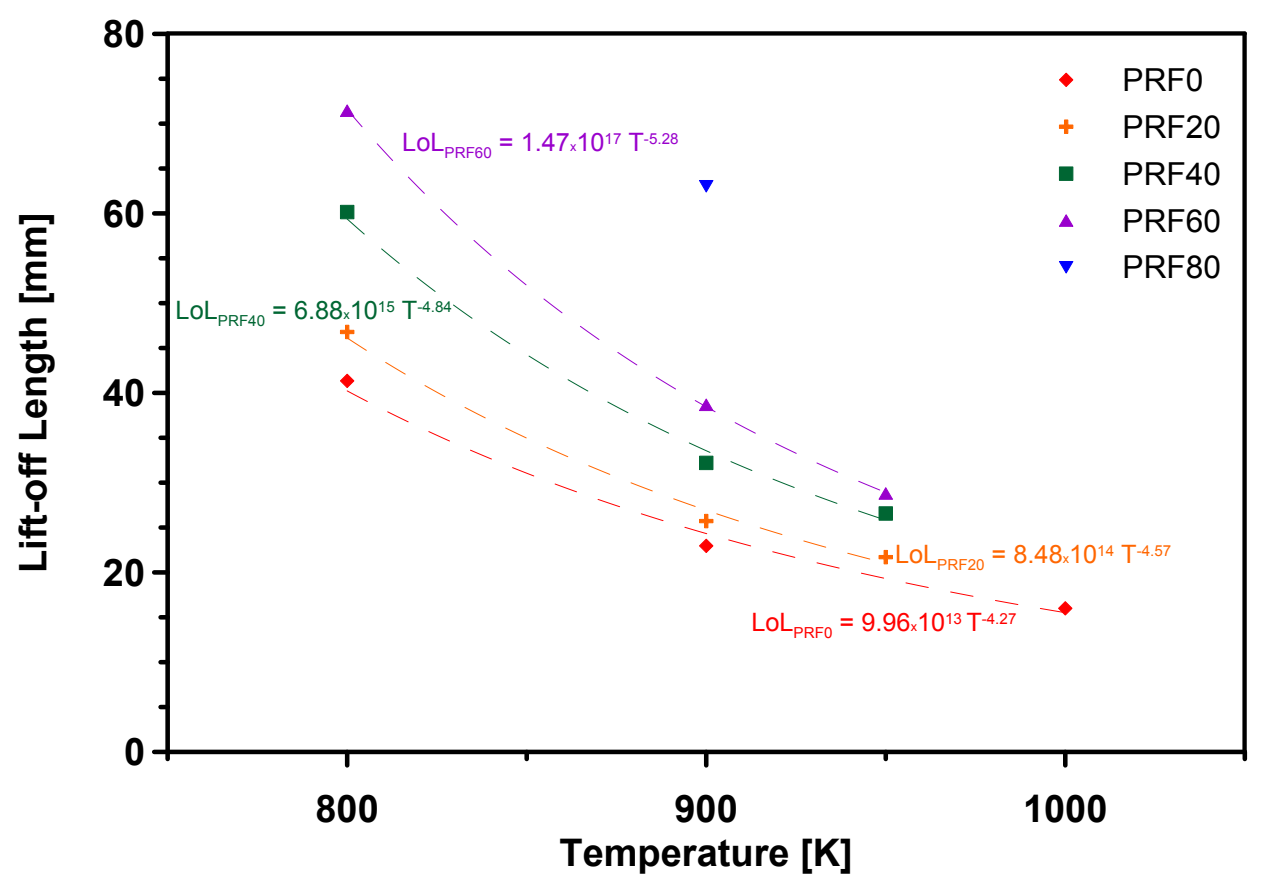

Figure 14: Lift-off length comparison under air temperature variation. 


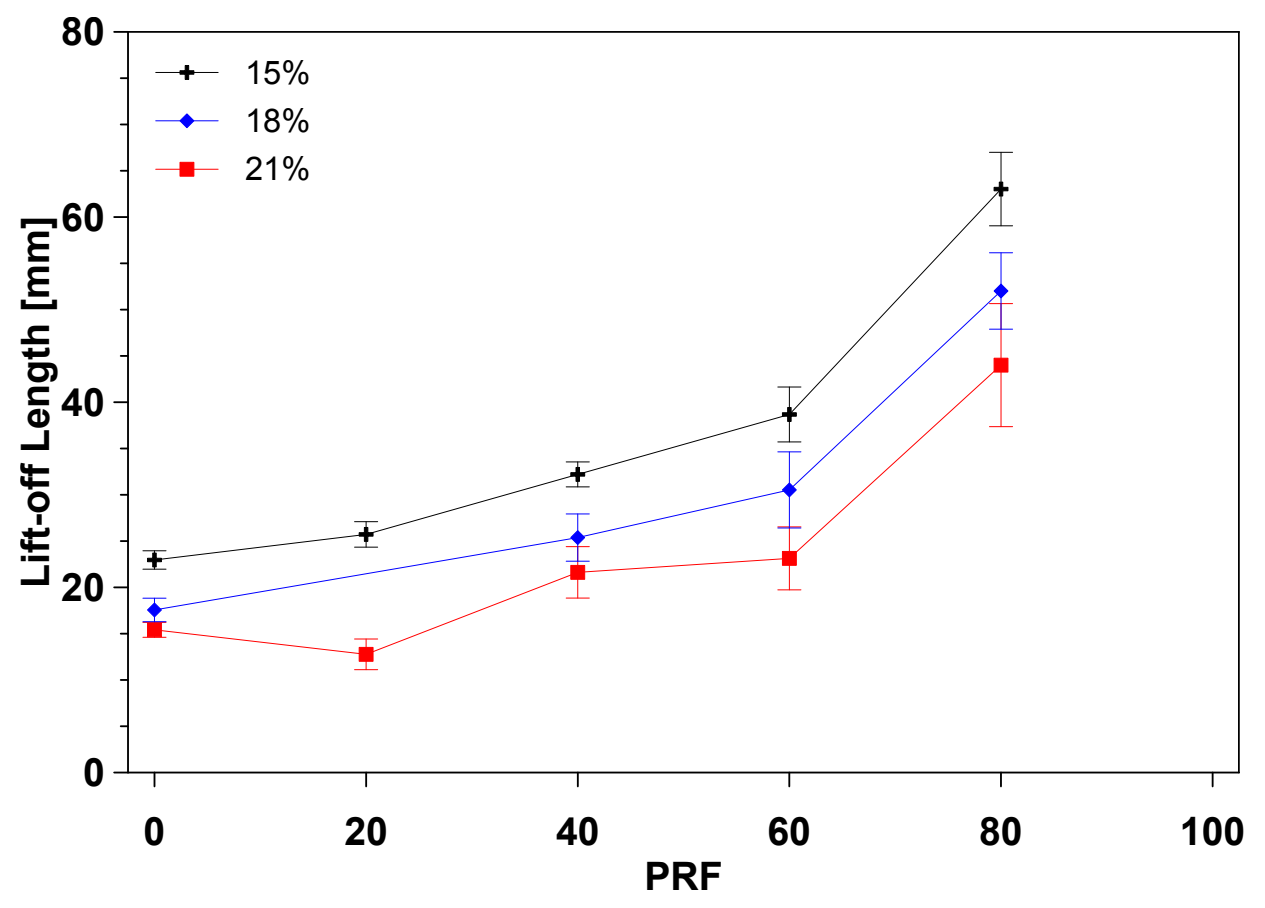

Figure 15: Lift-off length comparison under oxygen concentration variation. 


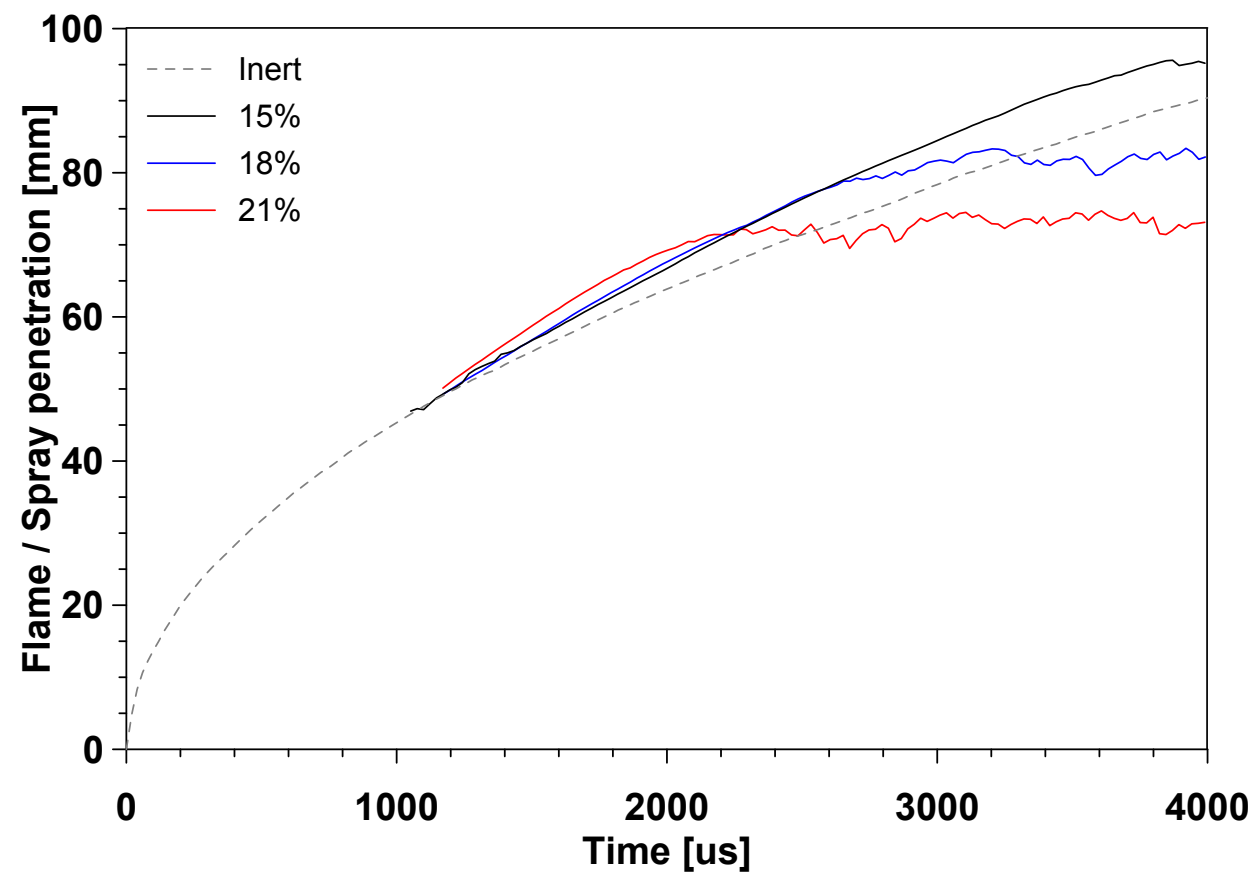

Figure 16: Flame length comparison for PRF0 under oxygen concentration variation at $900 \mathrm{~K}$ with inert spray penetration, time after SoI. 


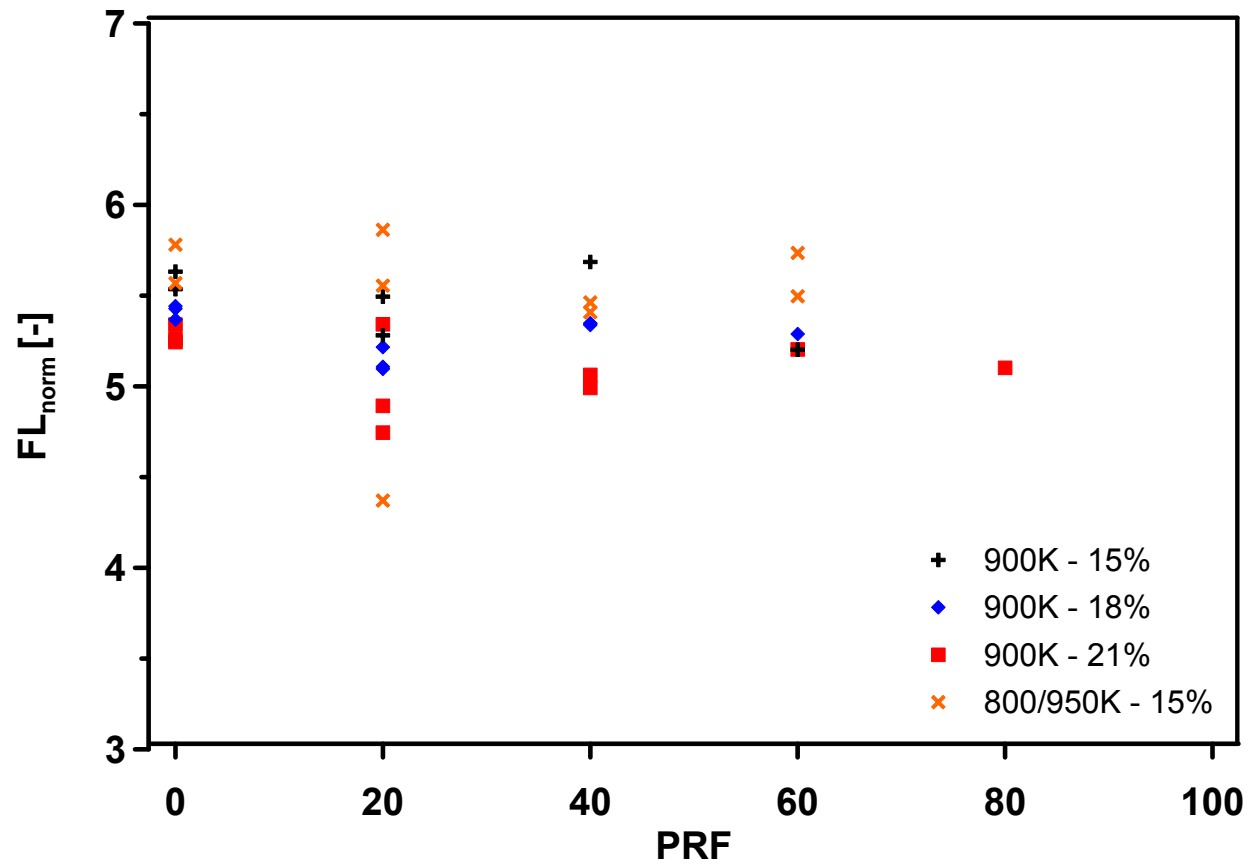

Figure 17: Normalized flame length $\left(F L_{\text {norm }}\right)$ versus fuel composition at ambient temperature and oxygen concentration variations. 
Table 1: Test matrix for parametric variation under reactive atmosphere. "A" indicates Spray-A standard conditions. All points performed at 150MPa of injection pressure and $22.8 \mathrm{~kg} / \mathrm{m}^{3}$ of ambient density. ${ }^{*}$ For PRF0, high temperature tests were performed at $1000 \mathrm{~K}$.

\begin{tabular}{|c||c|c|c|}
\hline$O_{2} \backslash T$ & $800 \mathrm{~K}$ & $900 \mathrm{~K}$ & $950 \mathrm{~K}^{*}$ \\
\hline \hline $15 \%$ & $\mathrm{X}$ & $\mathrm{A}$ & $\mathrm{X}$ \\
\hline $18 \%$ & & $\mathrm{X}$ & \\
\hline $21 \%$ & & $\mathrm{X}$ & \\
\hline
\end{tabular}


Table 2: Test matrix for inert conditions. "A" indicates Spray-A standard conditions. All points performed at $150 \mathrm{MPa}$ of injection pressure and $0 \%$ of oxygen concentration.

\begin{tabular}{|c||c|c|c|}
\hline$\rho \backslash T$ & $700 \mathrm{~K}$ & $800 \mathrm{~K}$ & $900 \mathrm{~K}$ \\
\hline \hline $15.2 \mathrm{~kg} / \mathrm{m}^{3}$ & & $\mathrm{X}$ & \\
\hline $22.8 \mathrm{~kg} / \mathrm{m}^{3}$ & $\mathrm{X}$ & $\mathrm{X}$ & $\mathrm{A}$ \\
\hline $45.6 \mathrm{~kg} / \mathrm{m}^{3}$ & & $\mathrm{X}$ & \\
\hline
\end{tabular}

